\title{
GOVERNANÇA CORPORATIVA EM EMPRESAS DE TRANSPORTE AÉREO
}

\section{CORPORATE GOVERNANCE IN AIR TRANSPORT ENTERPRISES}

\section{GOBIERNO CORPORATIVO EN EMPRESAS DE TRANSPORTE AÉREO}

\section{Frederico Lima Meneses}

Graduado em Administração pela Universidade de Brasília (UnB)

Endereço: UnB/FACE, Campus Universitário Darcy Ribeiro, CEP: CEP: 70910-900. Brasília, DF, Brasil Telefone: (61) 9 9971-9593

Email: frederico.meneses@gmail.com

\section{Carlos André de Melo Alves}

Doutor em Administração Faculdade de Economia, Administração, Contabilidade e Atuária (FEA/USP) Professor Adjunto - Departamento de Administração na UnB Endereço: UnB/FACE, Campus Universitário Darcy Ribeiro, CEP: CEP: 70910-900. Brasília, DF, Brasil Telefone: (61) 3107-0750

Email: carlosandre@unb.br

Artigo recebido em 05/12/2018. Revisado por pares em 10/04/2019. Reformulado em 11/04/2019. Recomendado para publicação em 02/12/2019. Publicado em 23/12/2019. Avaliado pelo Sistema double blind review. 


\section{RESUMO}

O objetivo deste artigo é analisar as características de governança corporativa de empresas de transporte aéreo considerando o nível de serviço, a região de atuação e o número de passageiros. Foi realizado um estudo descritivo, por meio da análise de conteúdo em estatutos, relatórios anuais e relatórios de tráfego de 34 empresas baseado nas recomendações da OCDE. Os resultados identificaram, em média, 66,91\% das subcategorias. Adicionalmente, não houve associação do percentual de presença de subcategorias ao nível de serviço e número de passageiros, entretanto, houve associação com relação à região de atuação.

Palavras-chave: Governança Corporativa; Transporte Aéreo; Recomendações da OCDE.

Analysis considering the service level, number of passengers and operating region.

\section{ABSTRACT}

The purpose of this article is to analyze the corporate governance characteristics of air transport companies considering the level of service, the region in which they operate and the number of passengers. A descriptive study was carried out, through content analysis in statutes, annual reports and traffic reports of 34 companies based on OECD recommendations. The results identified, on average, $66.91 \%$ of the subcategories. In addition, there was no association between the percentage of presence of subcategories in terms of service and number of passengers, however, there was an association in relation to the region in which they operate.

Keywords: Corporate Governance; Air Transport; OECD Recommendations.

Análisis considerando el nivel de servicio, el número de pasajeros y la región de actuación.

\section{RESUMEN}

El objetivo de este artículo es analizar las características de gobierno corporativo de empresas de transporte aéreo considerando el nivel de servicio, la región de actuación y el número de pasajeros. Se realizo um estúdio descriptivo, através del análisis de contenido en estatutos, informes anuales e informes de tráfico de 34 empresas basado em las recomendaciones de la OCDE. Los resultados identificaron, em promedio, el $66,91 \%$ de las subcategorías. Adicionalmente, no hubo asociación del porcentaje de presencia de subcategorías al nivel de servicio y número de pasajeros, sin embargo, hubo asociación com relación a la región de actuación.

Palavras clave: Gobierno Corporativo; Transporte Aéreo; Recomendaciones de la OCDE. 


\section{INTRODUÇÃO}

Constata-se, na atualidade, a importância logística da atuação das empresas de transporte para o fluxo de mercadorias e de pessoas nos diversos países. Entre tais empresas incluem-se aquelas atuantes no transporte aéreo. De acordo com o relatório anual da International Air Transport Association - IATA em 2016, as empresas de transporte aéreo foram responsáveis por aproximadamente $35 \%$ do volume de cargas transportadas e em torno de 3,5 bilhões de passageiros (IATA, 2017).

A realização de estudos sobre governança corporativa em empresas de transporte aéreo é de grande relevância dada as relações estabelecidas por tais empresas com diversas partes interessadas. O objetivo da governança corporativa, segundo a Organização para a Cooperação e Desenvolvimento Econômico - OCDE, é "ajudar a construir um ambiente de confiança, transparência e responsabilidade, necessário para fomentar o investimento a longo prazo, a estabilidade financeira e a integridade empresarial, apoiando, assim, um crescimento mais forte e sociedades mais inclusivas" (OCDE, 2016, p.7).

As empresas de transporte aéreo divulgam documentos institucionais para suas partes interessadas e as informações contidas nesses documentos podem contribuir para melhor caracterizar os princípios e práticas de governança corporativa, adotados por essas empresas. Uma vez que a OCDE é uma organização internacional que recebe contribuições de diversos países, especialmente dos países membros do G20, as recomendações a respeito de princípios e práticas de governança corporativa da OCDE podem ser consideradas para analisar as características de governança corporativa das empresas de transporte aéreo sediadas em diferentes países.

Além do número de passageiros citado no primeiro parágrafo desta introdução, as empresas de transporte aéreo podem ser avaliadas pelo nível de serviço oferecido, com base no ranking das melhores empresas aéreas do mundo (SKYTRAX, 2017), e podem ser divididas por região de atuação, levando em conta a localização da sede dessas empresas. Assim, o número de passageiros, o nível de serviço e a região de atuação podem ser empregados, inclusive, na análise das referidas características de governança corporativa dessas empresas. 


\subsection{PROBLEMA DE PESQUISA E OBJETIVO}

Considerando o contexto descrito previamente, o problema de pesquisa é o seguinte: quais são as características de governança corporativa de empresas de transporte aéreo considerando o nível de serviço, o número de passageiros e a região de atuação? Dessa forma, o objetivo deste estudo é analisar as características de governança corporativa de empresas de transporte aéreo considerando o nível de serviço, a região de atuação e o número de passageiros.

Realiza-se uma pesquisa descritiva com abordagem predominante qualitativa. A amostra dessa pesquisa é não-probabilística, compreendendo 34 empresas selecionadas a partir do ranking World Airline Awards da Skytrax de 2017. Os dados são coletados em estatutos, relatórios anuais e relatórios de tráfego. Para tratamento dos dados utiliza-se análise de conteúdo, empregando-se 20 subcategorias associadas a 4 categorias baseadas nas referidas recomendações da OCDE. Complementam-se as análises com uso das estatísticas descritiva e inferencial não paramétrica, empregando-se testes Qui-quadrado.

Alinhado ao que foi citado na introdução, a atuação das empresas de transporte aéreo é importante para a logística, especialmente para o fluxo de mercadorias e de pessoas nos diversos países. Nesse sentido, o estudo da governança corporativa dessas empresas é um tema relevante, já que pode contribuir para um melhor entendimento por parte de gestores, acadêmicos, reguladores, acionistas, órgãos do governo, entre outras partes interessadas na atuação dessas empresas. Em adição, esta pesquisa emprega variáveis pertinentes as empresas do setor aéreo como nível de serviço, região de atuação e número de passageiros, podendo contribuir para o estudo das características de governança corporativa de tais empresas.

\section{FUNDAMENTAÇÃO TEÓRICA}

\subsection{LOGÍSTICA E TRANSPORTE AÉREO}

De acordo com o Council of Supply Chain Management Professionals - CSCMP logística é o processo de planejamento, implantação e controle do fluxo eficiente e eficaz de 
mercadorias, serviços e das informações relativas desde o ponto de origem até o ponto de consumo com o propósito de atender às exigências dos clientes (CSCMP, 2013).

É importante ressaltar, dessa forma, que a logística pode ser estudada de forma isolada, mas cada vez mais vem sendo analisada num contexto integrado a outras funções para criar valor para os clientes (MENTZER et al., 2001). Esse valor gerado pelo processo logístico está associado à localização e ao tempo. O cliente deve estar de acordo com o local em que a empresa entregar determinado produto ou serviço, sendo que o local depende da possibilidade do transporte do produto (NOVAES, 2007).

No contexto da logística é importante estabelecer a delimitação do conceito de nível de serviço, como a qualidade com que o fluxo de bens e serviços é gerenciado (BALLOU, 1992). Para atingir determinado nível de serviço deve-se analisar seus elementos, que podem ser divididos em pré-transação, transação e pós-transação (BALLOU, 2006). Para que as empresas tenham um elevado nível de serviço devem manter-se atentas ao gerenciamento dos fluxos dos bens que produzem ou dos serviços que prestam.

Os diferentes modos de transporte podem ser agrupados em ferroviário, aquaviário, rodoviário, dutoviário (dutos) e aéreo. Em termos de velocidade, o transporte aéreo é o mais veloz, no entanto, se for considerado o tempo de entrega porta a porta, os benefícios da velocidade no transporte aéreo são percebidos, sobretudo, nas grandes distâncias (WANKE; FLEURY, 2006).

O transporte aéreo é útil para o comércio internacional e também para o setor de turismo, já que de acordo com a IATA (2017), só em 2016, os passageiros de empresas aéreas gastaram em torno de 650 bilhões de dólares, e no comércio internacional apurou-se o valor de 5,5 trilhões de dólares em cargas transportadas. Por sua vez, a Confederação Nacional do Transporte - CNT apresenta os seguintes comentários sobre a demanda dos serviços de transporte:

A demanda pelos serviços de transporte desse setor é determinada, entre outros fatores, pelo preço da passagem, pela variação da renda da população e pela disponibilidade de outros meios de transporte. Na indústria aérea, ela é normalmente representada em termos do número de passageiros embarcados, passageiros pagos por quilômetro (RPK) ou da tonelada paga por quilômetro (RTK). Seu comportamento pode ser caracterizado pelas flutuações constantes, pela 
sazonalidade e pela possibilidade de ocorrência de fluxos direcionais, entre outros (CNT, 2015, p. 13).

Os termos RPK e RTK são relacionados à demanda e ao desempenho no transporte aéreo e podem ser visualizados em relatórios de tráfego que são documentos disponibilizados geralmente com periodicidade mensal pelas empresas aéreas como forma de apresentação dos resultados obtidos e da gestão operacional dessas empresas.

Algumas das partes interessadas do setor aéreo devem ser lembradas: fornecedores de equipamentos, empresas de handling, responsáveis pelo controle de tráfego aéreo ou Air Traffic Control - ATC, empresas de catering, os fornecedores de tecnologia, os aeroportos e os órgãos reguladores (CNT, 2015). A descrição deles é detalhada na sequência.

Os fornecedores de equipamentos são um dos principais interessados, pois oferecem insumos para as aeronaves. As empresas de handling que são responsáveis pelos serviços prestados em terra que apoiam na atuação das empresas aéreas e dos aeroportos. O ATC, é quem orienta as aeronaves, tanto em solo quanto no ar, desta forma, o serviço prestado por ATC serve para garantir a rapidez, segurança e manter o fluxo de tráfego bem ordenado.

As empresas de catering que fornecem os alimentos e bebidas servidos nas aeronaves e as empresas fornecedoras de combustíveis que consomem grande parte dos custos que as empresas aéreas incorrem, em que de acordo com a CNT (2015) compreende a 37,30\% do custo de empresas aéreas no Brasil. Além das partes interessadas citadas nos parágrafos anteriores, pode-se apresentar os fornecedores de tecnologia para o setor, não só para as empresas aéreas, bem como para empresas de handling, entre outros.

Já os aeroportos são considerados os aeródromos públicos que possuem em sua infraestrutura instalações e que permitam o apoio ao embarque e desembarque de passageiros e das cargas transportadas, sem esquecer do apoio às empresas aéreas. Os aeroportos podem ser classificados em nacionais e internacionais, de acordo com a origem e destino dos voos que recebem. É importante frisar que os internacionais devem ainda ter uma infraestrutura diferenciada já que o porte das aeronaves que fazem rotas internacionais é maior, além de permitir o embarque de pessoas e cargas estrangeiras. Sendo necessário, ainda, a infraestrutura alfandegária para o controle de acesso tanto de pessoas quanto da carga transportada (Airports Council International- ACl, 2016). 
Outro elemento importante para o setor são os órgãos reguladores, já que são eles que limitam de certa forma como deve ser o comportamento das empresas que atuam neste e desta maneira permitem um ambiente mercadológico estável. No caso brasileiro, esse órgão é a Agência Nacional de Aviação Civil - ANAC, que tem como missão garantir a todos os brasileiros a segurança e a excelência, sendo que é responsável por atividades como certificação, fiscalização, normatização do setor, já nos Estados Unidos o responsável pela regulação do setor é a Federal Aviation Administration - FAA, sendo sua missão prover o sistema de espaço aéreo mais seguro e eficiente do mundo.

Na sequência, discorre-se sobre a avaliação das empresas aéreas, que pode ser feita com base em ranking anual no qual as melhores empresas avaliadas recebem o reconhecimento pelos serviços de excelência prestados aos seus passageiros. O ranking denominado como World Airline Awards - WAA é elaborado pela Skytrax, que se trata de uma organização de avaliação do transporte aéreo internacional.

Deve-se mencionar que a premiação citada no parágrafo anterior surgiu em 1999 através do lançamento da sua primeira pesquisa de satisfação dos passageiros acerca dos serviços prestados pelas empresas aéreas. A Skytrax avalia as empresas por meio de um questionário no qual os respondentes devem ranquear a satisfação com o serviço prestado pelas empresas de 1 a 5 a partir de três categorias principais: aeroporto/terra firme, produto a bordo e serviço na cabine. Tendo em vista estas informações, entende-se que o referido ranking pode ser usado como uma proxy para avaliar o nível de serviço ofertado por tais empresas a seus clientes.

Por meio do ranking WAA é possível observar ainda a região de atuação das empresas de transporte aéreo, que considerando as quinze primeiras colocadas no referido ranking, distribuem-se em regiões como Ásia, Oceania, Europa e Oriente Médio, demonstrando que as empresas de transporte aéreo possuem atuação em diversas regiões do mundo.

\subsection{GOVERNANÇA CORPORATIVA E RECOMENDAÇÕES DA OCDE}

De acordo com o Cadbury Report, governança corporativa é o sistema pelo qual as empresas são dirigidas e controladas (CADBURY, 1992). Para atingir os fins deste trabalho, buscou-se inicialmente apresentar aspectos conceituais sobre governança corporativa e 
outras características que pudessem abranger um número maior de nações e o contexto internacional de governança corporativa.

O estudo da governança corporativa possui estreita conexão com a teoria de agência, proposta por Jensen e Meckling (1976), baseada no relacionamento existente entre dois papéis: agente e principal. A abordagem para estudar a governança corporativa segundo a Teoria da Agência enfatiza os shareholders, que financiam as empresas por meio da compra de ações em mercados acionários espalhados pelo mundo e organizados pelas bolsas de valores como a B3 - Brasil, Bolsa, Balcão no Brasil e NYSE - New York Stock Exchange.

Existe outra abordagem para o estudo da governança corporativa, pautada na Teoria dos stakeholders, a qual argumenta que os interesses de partes interessadas devem ser considerados nos negócios (FREEMAN, 1994). Baseado na Teoria dos stakeholders, os gerentes articulam como eles querem fazer negócios, direcionado para o tipo de relacionamento que eles querem e precisam criar com seus stakeholders para alcançar o propósito da organização (FREEMAN; WICKS; PARMAR, 2004).

O contraste existente nas duas abordagens (enfatizando os shareholders $e$ os stakeholders) contribui para a o melhor entendimento da governança corporativa. Existe ainda uma proposta teórica que busca a conciliação entre as duas abordagens, buscando a maximização do valor para os acionistas e de forma que não se deixe de lado os interesses das outras partes interessadas, sendo esta abordagem denominada Enlightened Stakeholder Theory apresentada por Jensen (2002).

O estudo da governança corporativa aborda mecanismos de controle, divididos em mecanismos internos e externos. De acordo com Becht, Bolton, e Röell (2005) e Machado Filho (2006), dentre os mecanismos internos de governança corporativa estão: o papel dos conselhos, as políticas de remuneração e a estrutura de propriedade, no qual o último possui duas formas possíveis de identificação nas organizações, uma baseada na concentração e outra através de um formato disperso.

De acordo com OCDE (2016, p. 51) "O conselho de administração é o principal responsável por monitorar o desempenho de gestão e providenciar um retorno adequado aos acionistas, evitando conflito de interesses e equilibrando as exigências antagônicas no seio da 
empresa". O conselho de administração possui a responsabilidade final com relação ao funcionamento da organização. E acerca do seu papel, indica que os seguintes fatores como contratar, demitir, recompensar o diretor-executivo/presidente, além de fornecer aconselhamento de alto nível. Aspectos relacionados a tamanho de conselho também são estudados empiricamente (JENSEN, 1993).

Já os mecanismos externos, são baseados tanto na regulação como visto na seção 3.1 com exemplos da regulação da ANAC e FAA, quanto em mercados de capitais (inclusive o acionário). A OCDE traz o seguinte acerca dos mercados acionários: os mercados de ações podem desempenhar um papel significativo na melhoria do governo das sociedades através do estabelecimento e aplicação de requisitos que promovam o efetivo governo das sociedades pelos seus emitentes cotados em bolsa (OCDE, 2016).

Em relação ao sistema regulatório, Rabelo e Silveira (1999) destacam as diferenças de sistemas de governança corporativa considerando a distinção quanto ao ambiente legal e regulatório. Cada país ou região pode adotar suas próprias orientações legais e regulatórias, alinhado ao fato de existirem diferentes ambientes institucionais (NORTH, 1991). Sob a ótica da governança corporativa, pode-se estudar esta diferenciação conforme a região de atuação das empresas. Como exemplo, na Ásia, há o modelo japonês, um híbrido da orientação para o acionista e partes interessadas, enquanto o modelo anglo-saxão é mais orientado para os acionistas. Em complemento, alguns traços do predomínio de uma abordagem que privilegia partes interessadas podem ser encontrados, também, na Europa continental (SILVEIRA, 2010).

Após apresentar conceitos relativos à governança corporativa, inclusive princípios e práticas recomendadas pela OCDE, apresenta-se na Figura 1, contendo quatro categorias e vinte subcategorias baseadas no referencial teórico e nas citadas recomendações adaptadas para este estudo, especialmente aquelas presentes nos princípios 2, 4, 5 e 6 do documento da OCDE. As recomendações podem ser consideradas para caracterizar a governança corporativa de empresas de diversos setores, inclusive de transporte aéreo. Esse quadro conclui o referencial teórico e, na sequência, este trabalho apresentará a metodologia utilizada na realização desse estudo.

Quadro 1 - Categorias e subcategorias propostas para caracterizar governança corporativa em empresas de transporte aéreo 


\begin{tabular}{|c|c|}
\hline Categorias & Subcategorias \\
\hline \multirow{5}{*}{$\begin{array}{l}\text { 1. Controle Acionário e } \\
\text { Direito dos Acionistas }\end{array}$} & 1. Distribuição da propriedade em categorias de ações \\
\hline & 2. Diferenças do direito ao voto por categorias de ações \\
\hline & $\begin{array}{l}\text { 3. Menção a proporção ou ao percentual da distribuição da propriedade em } \\
\text { ações }\end{array}$ \\
\hline & 4. Menção a voto presencial ou por meio de procuração \\
\hline & 5. Menção ao direito de nomeação de conselheiros \\
\hline \multirow{5}{*}{$\begin{array}{l}\text { 2. Conselho de } \\
\text { Administração }\end{array}$} & 6. Quantidade de conselheiros \\
\hline & 7. Identificação das funções do conselho \\
\hline & 8. Número de membros do conselho executivos e não executivos \\
\hline & 9. Mandato dos conselheiros \\
\hline & 10. Menção a comitês especializados que dão apoio ao conselho \\
\hline \multirow{5}{*}{$\begin{array}{l}\text { 3. Relacionamento com } \\
\text { partes interessadas }\end{array}$} & $\begin{array}{l}\text { 11. Mecanismos de compensação dos direitos de fornecedores (aeronaves, } \\
\text { combustível ou tecnologia) }\end{array}$ \\
\hline & 12. Menção à atuação de órgãos reguladores \\
\hline & 13. Identificação de direitos dos credores \\
\hline & 14. Existência de ouvidoria \\
\hline & 15. Menção ao compartilhamento de lucros com os trabalhadores \\
\hline \multirow{5}{*}{ 4. Outras informações } & 16. Divulgação de resultados financeiros e operacionais \\
\hline & 17. Presença de auditoria interna \\
\hline & 18. Presença de auditoria independente \\
\hline & 19. Menção mecanismos para gerenciamento de riscos \\
\hline & 20. Menção a código de ética ou de conduta empresarial \\
\hline
\end{tabular}

Fonte: Elaborado pelos autores, com base em dados da pesquisa especialmente OCDE (2016), 2019.

\section{METODOLOGIA}

Esta pesquisa pode ser classificada como descritiva e sua abordagem é qualitativa e quantitativa. A pesquisa descritiva expõe características de determinada população ou de determinado fenômeno (VERGARA, 1998). A pesquisa descritiva pode ser utilizada, inclusive, para descobrir a existência de associações entre variáveis (GIL, 2002).

A população desta pesquisa é composta por empresas de transporte aéreo, sendo que sua escolha foi baseada na listagem destas, no ranking WAA 2017 da organização Skytrax que anualmente avalia as melhores empresas do setor, sendo avaliadas mais de 320 empresas, mas apenas lista-se as 100 mais bem colocadas (SKYTRAX, 2017). 
A amostra dessa pesquisa é considerada não-probabilística, na qual os indivíduos são selecionados com base em critérios tidos como relevantes pelos pesquisadores e participantes (GIL, 2002). A seleção das empresas da amostra deste estudo foi baseada nas etapas descritas na Figura 2, a partir das cem empresas melhores colocadas no citado ranking WAA de 2017, divulgado pela Skytrax.

Quadro 2 - Etapas para selecionar as empresas da amostra.

\begin{tabular}{|c|l|}
\hline Etapa & \multicolumn{1}{c|}{ Descrição da etapa } \\
\hline 1 & $\begin{array}{l}\text { Das cem empresas mais bem colocadas no ano } 2017 \text { foram selecionadas cinquenta e duas que } \\
\text { possuíam ações negociadas em bolsas de valores. }\end{array}$ \\
\hline 2 & $\begin{array}{l}\text { Em seguida, verificou-se a acessibilidade aos estatutos das empresas remanescentes da Etapa 1, } \\
\text { apurando-se que quarenta e uma delas possuíam seus estatutos com acesso público. }\end{array}$ \\
\hline 3 & $\begin{array}{l}\text { Apurou-se entre as quarenta e uma empresas remanescentes da Etapa } 2 \text { quantas delas } \\
\text { disponibilizam relatórios anuais, constatando-se que todas elas apresentaram estatutos } \\
\text { disponíveis. }\end{array}$ \\
\hline 4 & $\begin{array}{l}\text { Por fim, apurou-se a acessibilidade aos relatórios de tráfego das empresas remanescentes da Etapa } \\
\text { 3, constatando-se que trinta e quatro delas divulgaram tais relatórios. Essas trinta e quatro } \\
\text { empresas foram selecionadas para participar deste estudo. }\end{array}$ \\
\hline
\end{tabular}
Fonte: Elaborado pelos autores, com base em dados da pesquisa, 2019.

A Figura 3 descreve as trinta e quatro empresas da amostra, selecionadas conforme a Figura 2. A amostra exibe três regiões principais de atuação das empresas, identificadas com base nos respectivos estatutos: Américas (Norte-Central-Sul), Europa e Ásia-Oceania.

Quadro 3 - Descrição da amostra da pesquisa.

\begin{tabular}{|c|c|c|c|c|}
\hline $\begin{array}{c}\text { Posição Ranking WAA } \\
2017 \\
\end{array}$ & Empresa & $\begin{array}{l}\text { Região de } \\
\text { atuação }\end{array}$ & Nível de serviço & $\begin{array}{l}\text { Número de } \\
\text { passageiros }\end{array}$ \\
\hline 3 & ANA AllNippon Airways & Ásia-Oceania & Muito Grande & Grande \\
\hline 5 & Cathay Pacific Airways & Ásia-Oceania & Muito Grande & Médio \\
\hline 6 & EVA Air & Ásia-Oceania & Muito Grande & Médio \\
\hline 7 & Lufthansa & Europa & Muito Grande & Grande \\
\hline 11 & Thai Airways & Ásia-Oceania & Muito Grande & Médio \\
\hline 12 & Turkish Airlines & Ásia-Oceania & Muito Grande & Grande \\
\hline 13 & Virgin Australia & Ásia-Oceania & Muito Grande & Médio \\
\hline 15 & Qantas Airways & Ásia-Oceania & Muito Grande & Médio \\
\hline 18 & Air France - KLM & Europa & Grande & Grande \\
\hline 19 & Air New Zealand & Ásia-Oceania & Grande & Pequeno \\
\hline 21 & Bangkok Airways & Ásia-Oceania & Grande & Pequeno \\
\hline 23 & China Southern & Ásia-Oceania & Grande & Muito Grande \\
\hline 25 & Finnair & Europa & Grande & Médio \\
\hline 28 & Norwegian Air Shuttle & Europa & Grande & Médio \\
\hline
\end{tabular}




\begin{tabular}{|c|c|c|c|c|}
\hline $\begin{array}{c}\text { Posição Ranking WAA } \\
2017\end{array}$ & Empresa & $\begin{array}{l}\text { Região de } \\
\text { atuação }\end{array}$ & Nível de serviço & $\begin{array}{l}\text { Número de } \\
\text { passageiros }\end{array}$ \\
\hline 29 & Air Canada & Américas & Grande & Grande \\
\hline 30 & Aeroflot & Europa & Grande & Grande \\
\hline 32 & Delta Air Lines & Américas & Grande & Muito Grande \\
\hline 35 & China Airlines & Ásia-Oceania & Médio & Pequeno \\
\hline 36 & Alaska Airlines & Américas & Médio & Pequeno \\
\hline 38 & AerLingus (IAG) & Europa & Médio & Grande \\
\hline 39 & jetBlue Airways & Américas & Médio & Grande \\
\hline 52 & Azul Brazilian & Américas & Médio & Médio \\
\hline 54 & Southwest Airlines & Américas & Médio & Muito Grande \\
\hline 59 & LATAM & Américas & Médio & Grande \\
\hline 65 & SAS Scandinavian & Europa & Médio & Pequeno \\
\hline 72 & China Eastern Air & Ásia-Oceania & Médio & Muito Grande \\
\hline 74 & American Airlines & Américas & Pequeno & Muito Grande \\
\hline 76 & Ryanair & Europa & Pequeno & Muito Grande \\
\hline 78 & United Airlines & Américas & Pequeno & Muito Grande \\
\hline 82 & Icelandair & Europa & Pequeno & Pequeno \\
\hline 85 & Air Berlin & Europa & Pequeno & Médio \\
\hline 86 & Hawaiian Airlines & Américas & Pequeno & Pequeno \\
\hline 98 & Air China & Ásia-Oceania & Pequeno & Muito Grande \\
\hline 100 & Aeromexico & Américas & Pequeno & Pequeno \\
\hline
\end{tabular}

Fonte: Elaborado pelos autores, com base em Skytrax (2017) e dados da pesquisa, 2019.

Na Figura 3, o nível de serviço das companhias foi obtido a partir da segmentação em quartis do ranking de melhores empresas aéreas, mencionado na primeira coluna da figura. $\mathrm{O}$ número de passageiros na Figura 3 foi obtido a partir da segmentação em quartis do número de passageiros presentes nos relatórios de tráfego das empresas, considerando o primeiro semestre de 2017. A segmentação em quartis do nível de serviço e do número de passageiros subsidiou as análises dos resultados e baseou-se na literatura (ALVES, 2012).

A coleta dos dados foi realizada entre julho e agosto de 2017 a partir de estatutos e relatórios anuais disponibilizados pelas empresas e os mais recentes, além dos relatórios de tráfego compreendendo o primeiro semestre de 2017. Com relação ao tratamento dos dados, empregou-se a análise de conteúdo temático (BARDIN, 1997), e para viabilizar esse tipo de análise empregaram-se 20 subcategorias associadas a 4 categorias. As categorias e 
subcategorias baseiam-se nas recomendações da OCDE e constam da Figura 1, citada na Seção 3.2 do referencial teórico.

A técnica de enumeração da análise de conteúdo foi a presença ou ausência das subcategorias na documentação coletada de cada empresa da amostra. Dado que foram analisados os conteúdos dos documentos das 34 empresas aéreas da amostra e são 20 subcategorias, gerou-se 680 observações no total, e os resultados puderam ser agrupados por empresa, região de atuação, nível de serviço e número de passageiros citados na Figura 3. Para atingir os objetivos desta pesquisa, não foi preciso nomear as empresas nos resultados, sendo suficiente que fossem indicadas por um número aleatório para preservar suas identidades.

Por fim, para tratamento dos dados foi empregada, também, a estatística descritiva (média, mediana e desvio padrão), bem como a estatística inferencial, por meio de testes Quiquadrado (SIEGEL; CASTELLAN, 2006). Os testes foram realizados por meio do software Statistical Package for the Social Sciences - SPSS, versão 22.0.

\section{ANÁLISE DOS RESULTADOS}

Esta seção exibe os resultados das análises das características de governança corporativa por empresa de transporte aéreo, sendo especificado ainda análises por nível de serviço, por região de atuação e número de passageiros, levando em conta a análise de conteúdo realizada baseada nas categorias e subcategorias da Figura 1. Inicialmente, a Tabela 1 mostra a consolidação dos dados por empresa.

Tabela 1 - Frequência de subcategorias por Empresa de Transporte Aéreo.

\begin{tabular}{|c|c|c|c|c|c|c|c|}
\hline $\begin{array}{c}\text { Empresa de } \\
\text { Transporte Aéreo }\end{array}$ & A & $\mathbf{P}$ & $\begin{array}{l}P \\
(\%)\end{array}$ & $\begin{array}{l}\text { Empresa de } \\
\text { Transporte Aéreo }\end{array}$ & A & $\mathbf{P}$ & $\begin{array}{l}P \\
(\%)\end{array}$ \\
\hline 2 & 4 & 16 & 80,00 & 28 & 6 & 14 & 65,00 \\
\hline 8 & 4 & 16 & 80,00 & 29 & 6 & 14 & 65,00 \\
\hline 16 & 4 & 16 & 80,00 & 3 & 7 & 13 & 65,00 \\
\hline 17 & 4 & 16 & 80,00 & 5 & 7 & 13 & 65,00 \\
\hline 4 & 5 & 15 & 75,00 & 15 & 7 & 13 & 65,00 \\
\hline 6 & 5 & 15 & 75,00 & 21 & 7 & 13 & 65,00 \\
\hline 12 & 5 & 15 & 75,00 & 25 & 7 & 13 & 65,00 \\
\hline
\end{tabular}




\begin{tabular}{c|c|c|c|c|c|c|c}
\hline $\begin{array}{c}\text { Empresa de } \\
\text { Transporte Aéreo }\end{array}$ & A & $\mathbf{P}$ & $\begin{array}{c}\mathbf{P} \\
\mathbf{( \% )}\end{array}$ & $\begin{array}{c}\text { Empresa de } \\
\text { Transporte Aéreo }\end{array}$ & $\mathbf{A}$ & $\mathbf{P}$ & $\begin{array}{c}\text { P } \\
\text { (\%) }\end{array}$ \\
\hline 24 & 5 & 15 & 75,00 & 10 & 7 & 13 & 65,00 \\
\hline 27 & 5 & 15 & 75,00 & 18 & 8 & 12 & 60,00 \\
\hline 31 & 5 & 15 & 75,00 & 20 & 8 & 11 & 60,00 \\
\hline 32 & 5 & 15 & 75,00 & 26 & 9 & 11 & 55,00 \\
\hline 14 & 5 & 15 & 75,00 & 34 & 10 & 10 & 50,00 \\
\hline 1 & 6 & 14 & 70,00 & 7 & 10 & 10 & 50,00 \\
\hline 11 & 6 & 14 & 70,00 & 23 & 10 & 10 & 50,00 \\
\hline 19 & 6 & 14 & 70,00 & 30 & 10 & 10 & 50,00 \\
\hline 22 & 6 & 14 & 70,00 & 33 & 11 & 9 & 45,00 \\
\hline
\end{tabular}

Legenda: P - Quantidade de subcategorias presentes; A - Quantidade de subcategorias ausentes; P\% Percentual de subcategorias presentes.

Obs.: A tabela está ordenada pelo percentual de presença das subcategorias apresentado por cada Empresa de Transporte Aéreo, em ordem decrescente.

Fonte: Elaborado pelos autores, com base em dados da pesquisa, 2019.

Com os dados expostos na Tabela 1 foi realizada uma análise descritiva com base nos percentuais de presença das subcategorias observadas na determinada amostra. Sendo que o resultado dessa análise pode ser observado na Tabela 2 que apresenta dados como média, mediana, desvio padrão, os mínimos e máximos observados e por último as divisões dos percentuais em quartis.

Tabela 2 - Análise descritiva - Frequência de subcategorias por empresa de transporte aéreo.

\begin{tabular}{c|c|c|c|c|c|c|c}
\hline \multirow{2}{*}{ N } & \multirow{2}{*}{ Média } & DP & \multirow{2}{*}{ Mín. } & \multirow{2}{*}{ Máx. } & \multicolumn{3}{|c}{ Quartis } \\
\cline { 5 - 8 } & & & & & 10 Quartil & Mediana & 30 Quartil \\
\hline 34 & $66,91 \%$ & $10,00 \%$ & $45,00 \%$ & $80,00 \%$ & $60,00 \%$ & $70,00 \%$ & $75,00 \%$ \\
\hline
\end{tabular}

Legenda: N - número de empresas; DP - Desvio padrão; Mín. - Mínimo; Máx. - Máximo.

Fonte: Elaborado pelos autores, com base em dados da pesquisa, 2019.

É possível observar que a média, apresentada na Tabela 2 corresponde aos valores 66,91\%, sendo que o mínimo de presença das subcategorias observadas em uma empresa foi de $45,00 \%$, já o máximo correspondeu a $80,00 \%$ das subcategorias. Observou-se o desvio padrão igual a $10,00 \%$ e a mediana foi $70,00 \%$.

A Tabela 3 mostra os resultados da análise das características de governança corporativa das empresas de transporte aéreo segmentadas por nível de serviço. A referida tabela mostra as frequências observadas, juntamente com os respectivos percentuais e os 
resultados do teste Qui-Quadrado. Verifica-se que o percentual de presença das subcategorias considerando as empresas vinculadas à categoria 'muito grande' foi igual a $70 \%$. Já o percentual de presença de subcategorias levando em conta as empresas da categoria 'grande' obteve $63,89 \%$.

Tabela 3 - Frequência por nível de serviço e Teste Qui-Quadrado.

\begin{tabular}{|c|c|c|c|c|c|c|}
\hline \multirow[b]{2}{*}{ Nível de Serviço } & \multicolumn{2}{|c|}{ Divulgação } & \multirow{2}{*}{$\begin{array}{c}\text { Total } \\
\text { (\%) }\end{array}$} & \multirow[b]{2}{*}{ Qui-Quadrado } & \multirow[b]{2}{*}{ GL } & \multirow[b]{2}{*}{ Significância } \\
\hline & $\begin{array}{l}A \\
(\%)\end{array}$ & $\begin{array}{c}P \\
(\%)\end{array}$ & & & & \\
\hline Muito Grande & $\begin{array}{c}48 \\
(30,00)\end{array}$ & $\begin{array}{c}112 \\
(70,00)\end{array}$ & $\begin{array}{c}160 \\
(100,00)\end{array}$ & \multirow{4}{*}{$1,44^{1}$} & \multirow{4}{*}{3} & \multirow{4}{*}{0,69} \\
\hline Grande & $\begin{array}{c}65 \\
(36,10)\end{array}$ & $\begin{array}{c}115 \\
(63,90)\end{array}$ & $\begin{array}{c}180 \\
(100,00)\end{array}$ & & & \\
\hline Médio & $\begin{array}{c}59 \\
(32,78)\end{array}$ & $\begin{array}{c}121 \\
(67,22)\end{array}$ & $\begin{array}{c}180 \\
(100,00)\end{array}$ & & & \\
\hline Pequeno & $\begin{array}{c}53 \\
(33,12)\end{array}$ & $\begin{array}{c}107 \\
(66,88)\end{array}$ & $\begin{array}{c}160 \\
(100,00)\end{array}$ & & & \\
\hline
\end{tabular}

Legenda: A - Ausência; P - Presença; GL - graus de liberdade. Obs: ${ }^{1} \mathrm{O}$ teste Qui-Quadrado foi realizado com todos os requisitos atendidos. Fonte: Elaborado pelos autores, com base em dados da pesquisa, 2019.

Na Tabela 3 é possível observar o resultado do teste Qui-Quadrado com um valor estatístico igual a 1,44, tendo 3 graus de liberdade e com uma significância de 0,69 , sendo possível afirmar que não houve diferenças significativas. Em outras palavras, esse resultado indicou não haver associação entre nível de serviço exposto na seção 3.1 do referencial teórico, e o percentual de subcategorias presentes relacionadas às características de governança corporativa.

A Tabela 4 apresenta os resultados da análise das características de governança corporativa das empresas de transporte aéreo segmentadas por número de passageiros. A citada tabela mostra as frequências observadas, os percentuais relacionados a essas frequências, juntamente com o resultado do teste Qui-Quadrado. Pode-se ressaltar do resultado mostrado na Tabela 5 que o percentual de presença das subcategorias considerando as empresas vinculadas à categoria 'médio' foi igual a 69,44\%. Já o percentual de presença de subcategorias levando em conta as empresas da categoria 'grande' obteve 63,89\%.

Tabela 4 - Frequência por número de passageiros e Teste Qui-Quadrado 


\begin{tabular}{|c|c|c|c|c|c|c|}
\hline \multirow{2}{*}{$\begin{array}{l}\text { Número de } \\
\text { Passageiros }\end{array}$} & \multicolumn{2}{|c|}{ Divulgação } & \multirow{2}{*}{$\begin{array}{c}\text { Total } \\
\text { (\%) }\end{array}$} & \multirow[b]{2}{*}{ Qui-Quadrado } & \multirow[b]{2}{*}{ GL } & \multirow[b]{2}{*}{ Significância } \\
\hline & $\begin{array}{l}\text { A } \\
\text { (\%) }\end{array}$ & $\begin{array}{l}P \\
(\%)\end{array}$ & & & & \\
\hline Muito Grande & $\begin{array}{c}52 \\
(33,50)\end{array}$ & $\begin{array}{c}108 \\
(67,50)\end{array}$ & $\begin{array}{c}160 \\
(100,00)\end{array}$ & \multirow{4}{*}{$1,29^{1}$} & \multirow{4}{*}{3} & \multirow{4}{*}{0,73} \\
\hline Grande & $\begin{array}{c}65 \\
(36,11)\end{array}$ & $\begin{array}{c}115 \\
(63,89)\end{array}$ & $\begin{array}{c}180 \\
(100,00)\end{array}$ & & & \\
\hline Médio & $\begin{array}{c}55 \\
(30,56)\end{array}$ & $\begin{array}{c}125 \\
(69,44)\end{array}$ & $\begin{array}{c}180 \\
(100,00)\end{array}$ & & & \\
\hline Pequeno & $\begin{array}{c}53 \\
(33,12)\end{array}$ & $\begin{array}{c}107 \\
(66,88)\end{array}$ & $\begin{array}{c}160 \\
(100,00)\end{array}$ & & & \\
\hline
\end{tabular}

Legenda: A - Ausência; P - Presença; GL - graus de liberdade.

Obs: ${ }^{1} O$ teste Qui-Quadrado foi realizado com todos os requisitos atendidos.

Fonte: Elaborado pelos autores, com base em dados da pesquisa, 2019.

Na Tabela 4 é possível observar o resultado do teste Qui-Quadrado com um valor estatístico igual a 1,29, tendo 3 graus de liberdade e com uma significância de 0,73 , sendo possível afirmar que não houve diferenças significativas. Desta forma, não houve associação entre número de passageiros transportados pelas empresas como exposto na seção 3.1 , e o percentual de subcategorias presentes relacionadas às características de governança corporativa.

A Tabela 5 apresenta os resultados da análise das características de governança corporativa das empresas de transporte aéreo segmentadas por região de atuação. Na citada tabela constam as frequências observadas, os percentuais relacionados a essas frequências, juntamente com o resultado do teste Qui-Quadrado.

Tabela 5 - Frequência por região de atuação e Teste Qui-Quadrado.

\begin{tabular}{|c|c|c|c|c|c|c|}
\hline \multirow[b]{2}{*}{ Região de Atuação } & \multicolumn{2}{|c|}{ Divulgação } & \multirow{2}{*}{$\begin{array}{c}\text { Total } \\
\text { (\%) }\end{array}$} & \multirow[b]{2}{*}{ Qui-Quadrado } & \multirow[b]{2}{*}{ GL } & \multirow[b]{2}{*}{ Significância } \\
\hline & $\begin{array}{l}\text { A } \\
(\%)\end{array}$ & $\begin{array}{l}P \\
(\%)\end{array}$ & & & & \\
\hline Ásia-Oceania & $\begin{array}{c}72 \\
(27,70)\end{array}$ & $\begin{array}{c}188 \\
(72,30)\end{array}$ & $\begin{array}{c}260 \\
(100,00)\end{array}$ & \multirow{3}{*}{$6,55^{1}$} & \multirow{3}{*}{2} & \multirow{3}{*}{$0,03 * *$} \\
\hline Américas & $\begin{array}{c}85 \\
(38,60)\end{array}$ & $\begin{array}{c}135 \\
(61,40)\end{array}$ & $\begin{array}{c}220 \\
(100,00)\end{array}$ & & & \\
\hline Europa & $\begin{array}{c}68 \\
(34,00)\end{array}$ & $\begin{array}{c}132 \\
(66,00)\end{array}$ & $\begin{array}{c}200 \\
(100,00)\end{array}$ & & & \\
\hline
\end{tabular}

Legenda: A - Ausência; P - Presença; GL - graus de liberdade. 
Obs: **Significativo a 5\%; 10 teste Qui-Quadrado foi realizado com todos os requisitos atendidos.

Fonte: Elaborado pelos autores, com base em dados da pesquisa, 2019.

A Tabela 5 mostra que o resultado do teste Qui-Quadrado foi 6,55, tendo 3 graus de liberdade e com uma significância de 0,03, sendo, portanto, evidenciada a existência de diferenças na proporção de subcategorias presentes levando-se em conta a região de atuação das empresas analisadas. As empresas de transporte aéreo, sediadas no continente asiático e na Oceania apresentaram um percentual de presença de subcategorias igual a $72,31 \%$. No que Ihe concerne, as empresas sediadas nas Américas apresentaram percentual de presença de $61,36 \%$.

Por fim, os resultados exibidos na Tabela 5 sugerem que a região de atuação das empresas de transporte aéreo da amostra condiciona o percentual de subcategorias presentes relativas às características de governança corporativa, revelando indícios de uma maior aderência das subcategorias nas empresas da região Ásia-Oceania. Com base na seção 2.2 da fundamentação teórica, verificou-se que o país de atuação da empresa de transporte aéreo pode estar associado a um modelo de governança corporativa específico. Por exemplo, na Ásia, há o modelo japonês, um híbrido da orientação para o acionista e partes interessadas, enquanto o modelo anglo-saxão é mais orientado para os interesses dos acionistas.

\section{CONCLUSÃO}

O objetivo desta pesquisa foi analisar as características de governança corporativa de empresas de transporte aéreo considerando o nível de serviço, o número de passageiros e a região de atuação. Este estudo tratou um tema relevante, podendo contribuir para um melhor entendimento por parte de gestores, acadêmicos, acionistas entre outros interessados nas características de governança corporativa de empresas de transporte aéreo atuantes no Brasil e no exterior.

Para atingir o objetivo foi realizada uma pesquisa descritiva, predominantemente qualitativa. A coleta e o tratamento dos dados efetuaram-se por meio da análise de conteúdo dos documentos divulgados pelas 34 empresas de transporte aéreo componentes da amostra, considerando 20 subcategorias associadas a 4 categorias baseadas especialmente nas recomendações da OCDE. 
Os principais resultados permitiram verificar o percentual médio de divulgação das subcategorias presentes usados para caracterizar a governança corporativa das empresas de transporte aéreo foi de $66,91 \%$. Entretanto, esse percentual não foi distribuído de maneira uniforme entre as empresas segundo a região de atuação. As empresas da região que agrupava o continente Asiático e a Oceania apresentaram percentual de presença de $72,31 \%$, e as empresas sediadas nas Américas obtiveram a presença em 61,36\%.

Adicionalmente, os resultados permitiram constatar que não houve diferenças entre as características de governança corporativa de empresas de transporte aéreo segundo o nível de serviços oferecidos. Apurou-se, também, que o percentual de subcategorias presentes não se condiciona ao número de passageiros das empresas de transporte aéreo.

Este trabalho tratou de um tema atual, dada a importância das empresas de transporte aéreo no cenário logístico, especialmente no transporte de cargas e de passageiros. Adicionalmente, buscou fornecer subsídios para o acompanhamento das empresas de transporte aéreo por parte das agências reguladoras, podendo contribuir para aprimorar parâmetros relacionados à regulação do setor. É adequado informar que a coleta dos dados foi transversal. Adicionalmente, a escolha das empresas da amostra considerou a acessibilidade dos documentos públicos.

Por fim, considerando o que foi exposto, é recomendado propor a realização de estudos futuros, que podem complementar os achados desta pesquisa. Novas análises poderão considerar, por exemplo, outros períodos para a coleta dos dados. Adicionalmente, pode-se estudar outras empresas de transporte aéreo que não participaram da amostra desta pesquisa e que venham a disponibilizar documentos publicamente. É possível, também, realizar estudos de caso comparando as características de governança corporativa das empresas de transporte aéreo da Ásia e Oceania com empresas de outras regiões do mundo.

\section{REFERÊNCIAS}

ACI. AIRPORTS COUNCIL INTERNATIONAL. Annual Report, 2016. Disponível em: http://www.aci.aero/Publications/New-Releases/ACl-Annual-Report-2016-The-voice-of-theworlds-airports. Acesso em: 10 de Setembro de 2017.

\section{ALVES, C.A.M. As contribuições das ouvidorias para a gestão e para a governança}

corporativa: estudo em instituições bancárias baseado na regulamentação brasileira. 2012. 
Tese (Doutorado em Administração) - Faculdade de Economia, Administração e Contabilidade, Universidade de São Paulo, São Paulo, p. 191, 2012.

BALLOU. R. H. Gerenciamento da Cadeia de Suprimentos / Logística Empresarial. 5a ed. Porto Alegre: Bookman, 2006.

BALLOU. R. H. Logística Empresarial: transportes, administração de materiais e distribuição física. São Paulo: Atlas. 1992.

BARDIN, L. Análise de Conteúdo. Lisboa: Edições 70 Ltda., 1997.

BECHT, M.; BOLTON, P.; RÖELL, A. Corporate Governance and Control. European ECGI Working Paper Serie in Finance. Corporate Governance Institute. 2005.

CADBURY REPORT. The Report of the Committee on the Financial Aspects of Corporate Governance. The Committee on the Financial Aspects of Corporate Governance and Geeand Co. Ltd. 1992.

CNT. CONFEDERAÇÃO NACIONAL DO TRANSPORTE. Transporte e economia: transporte aéreo de passageiros, 2015. Disponível em:

http://cms.cnt.org.br/Imagens\%20CNT/Site\%202015/Pesquisas\%20PDF/

Transporte\%20e\%20Economia\%20Transporte\%20A\%C3\%A9reo\%20de\%20Passageiros.pdf . Acesso em 12 de Setembro de 2017.

CSCMP. COUNCIL OF SUPPLY CHAIN MANAGEMENT PROFESIONALS. Supply Chain Management: Terms and Glossary. 2013. Disponível em:

http://cscmp.org/CSCMP/Educate/SCM_Definitions_and_Glossary_of_Terms/CSCMP/Educat e/SCM_Definitions_and_Glossary_of_Terms.aspx?hkey=60879588-f65f-4ab5-8c4b6878815ef921. Acesso em: 10 de Setembro de 2017.

FREEMAN, R. E. The Politics of the Stakeholders Theory: Some Future Directions. Business Ethics Quarterly 4 (4), p.409-421. 1994.

FREEMAN, R. E., WICKS, A. C. \& PARMAR B. Stakeholder Theory and "The Corporate Objective Revisited”. Organization Science. Vol. 15, No. 3, p. 364-369. 2004.

GIL, A. C. Como Elaborar Projetos de Pesquisa. 4ạ Edição. São Paulo: Atlas, 2002.

IATA. International Air Transport Association. Annual Review, 2017. Disponível em: https://www.iata.org/ publications/Documents/iata-annual-review-2017.pdf. Acesso em: 10 de Setembro de 2017.

JENSEN, C. M. The Modern Industrial Revolution, Exit, and the Failure of Internal Control Systems. The Journal of Finance, V. 48, N. 3, p. 831-880. 1993. Disponível em: http://dx.doi.org/10.1111/j.1540-6261.1993.tb04022.x. Acesso em: 25 de Setembro. 2017. 
JENSEN, C. M. Value Maximization, Stakeholder Theory, and the Corporate Objective Function. Business Ethics Quarterly. Vol. 12, No. 2, p. 235-256. 2002. Disponível em: http://www.jstor.org/stable/3857812. Acesso em: 23 de Setembro. 2017.

JENSEN, C. M. \& MECKLING W. H. Theory of the Firm: Managerial Behaviour, Agency Costs, and Owner ship Structure. Journal of Financial Economics. V. 3, p. 305-360. 1976. MACHADO FILHO, C. A. P. Responsabilidade Social e Governança. O debate e as implicações. São Paulo: Thomson, 2006.

MENTZER, J. T et al. Defining Supply Chain Management. Journal of Business Logistics, V. 22, N. 2, p.1-25. 2001.

NORTH, D. C. Economic Performance through Time. The American Economic Review, 84 (3), 359-368. 1994.

NOVAES, Antônio Galvão. Logística e Gerenciamento da Cadeia de Distribuição. Rio de Janeiro: Elsevier, 2007.

OCDE. Organização para a Cooperação e Desenvolvimento Econômico. Princípios de Governo das Sociedades do G20 e da OCDE. Paris, Éditions OCDE. 2016.

RABELO, F. e SILVEIRA, J. M. Estruturas de Governança e Governança Corporativa: avançando na direção da integração entre as dimensões competitivas e financeiras. Texto para Discussão. IE/UNICAMP, Campinas, n. 77, Julho, 1999.

SILVEIRA, A.D. M. Governança corporativa no Brasil e no mundo: teoria e prática. Rio de Janeiro: Elsevier, 2010.

VERGARA, S. C. Projetos e Relatórios de Pesquisa em Administração. 2ª Edição. São Paulo: Atlas. 1998.

SIEGEL, S.; CASTELLAN JR., N. J. Estatística não-paramétrica para ciências do comportamento. 2. ed. Porto Alegre: Artmed Editora S.A., 2006.

SKYTRAX. World Airline Awards. 2017. Disponível em:

<http://www.worldairlineawards.com/Awards/worlds_best_airline.html>. Acesso em: 08 Setembro. 2017.

WANKE, P. F.; FLEURY, P. F. Transporte de cargas no Brasil: estudo exploratório das principais variáveis relacionadas aos diferentes modais e às suas estruturas de custos. In: DE NEGRI, J. A.; KUBOTA, L. C. (Org.). Estrutura e Dinâmica do Setor de Serviços no Brasil. Brasília: IPEA, 2006.

\footnotetext{
${ }^{1}$ Ao abordar a logística empresarial, esta pesquisa tem o foco no transporte aéreo, sem prejuízo de que outras pesquisas possam estudar a logística integrada a funções como finanças e marketing. $O$ estudo da logística integrada pode, também, ser encontrado na literatura como associado ao gerenciamento da cadeia de suprimentos (BALLOU, 2006).
} 